\title{
Crítica contemporânea da telenovela brasileira
}

\section{Contemporary criticism of Brazilian telenovela}

Mariana Marques de Limaํ e Maria Immacolata Vassallo de Lopes² do Centro de Estudos de Telenovela (CETVN/USP) e da rede de pesquisadores do Observatório Ibero-americano de Ficção Televisiva (Obitel). E-mail: marit.mlima@gmail.com. 


\section{Resumo}

O presente artigo analisa a crítica de telenovela realizada e veiculada no ambiente digital dos anos de 2012 a 2018, a partir do estudo dos críticos Maurício Stycer e Cristina Padiglione. Nosso objetivo principal é apreender a função dessa crítica de telenovela contemporânea, compreendendo suas características no cenário brasileiro e sua circulação de sentidos. Para isso, analisamos as críticas e entrevistas desses profissionais, entrevendo seus processos de escrita, repertórios e tipos de avaliações. Os resultados mostram que essa crítica atual privilegia análises de caráter estético, reflexões sobre as características da telenovela brasileira e o próprio lugar da crítica; bem como uma pauta de valores, em que emergem os elementos políticos e uma demanda para questões sociais apresentadas nas ficções, evidenciando uma crítica que incide e dialoga com as questões da sociedade.

\section{Palavras-chave}

Telenovela, crítica, circulação de sentidos, críticos.

\section{Abstract}

The article analyzes the telenovela criticism carried out and broadcasted in the digital environment between the years 2012 and 2018, based on the study by critics Maurício Stycer and Cristina Padiglione. Our main objective is to apprehend the role of this contemporary telenovela criticism, understanding its characteristics in the Brazilian scenario and its circulation of meanings. For this, we analyze the criticism and interviews of these professionals, seeing their writing processes, repertoires and types of evaluations. The results show that this current criticism privileges analyzes of aesthetic nature, reflections on the characteristics of Brazilian telenovela and the very function of criticism; as well as a list of values, in which the political elements emerge and a demand for social issues presented in the fictions, showing a criticism that affects and dialogues with the issues of society.

\section{Keywords}

Telenovela, Criticism, Circulation of meanings, Critics. 
Este artigo apresenta uma análise qualitativa e quantitativa dos trabalhos de dois críticos de telenovela com a finalidade de entender como se efetua essa crítica em suas páginas digitais. A crítica de telenovela tem um papel central de interpretação de formas culturais, diferindo da crítica de cinema, de teatro e da literatura, pois a telenovela é um produto em construção, obra aberta de longa serialidade. A prática dessa crítica demanda tempo para o acompanhamento da obra e, ao mesmo tempo, é rápida, visto que, após determinado capítulo, o crítico deve discorrer sobre o que foi transmitido. A maturação do pensamento para o tratamento de uma ficção ocorre ao longo da narrativa, que dura em média oito meses; e nesse período, a crítica e o crítico conversam com seu púbico, bem como com os próprios produtores desse conteúdo.

Esse dialogismo ou semiose social (VERÓN, 1987) da telenovela atende especificamente às formas que essa crítica tomou e como ela foi se consolidando com os anos, pois esses profissionais, acompanharam as transformações do formato 3 e, por meio de seus repertórios, estabeleceram um modelo próprio de análise. Esse processo de instauração de uma competência televisiva foi abarcado pela população brasileira e independentemente dos inúmeros ruídos e das divergências, a televisão abriga um papel importante na seleção de discursos circulantes, que correspondem à "soma empírica de enunciados com visada definicional sobre o que são os seres, as ações, os acontecimentos, suas características, seus comportamentos e os julgamentos a eles ligados" (CHARAUDEAU, 2006, p. 118). No dizer de Gomes (2012, p. 16), "esses discursos se espalham em vários campos do saber e vão se atualizando dependendo do período histórico e do lugar, o que, consequentemente, designa modos de ser.

Esse repertório comum promovido pela telenovela possibilita a expertise para sua análise. No entanto, a compreensão desse formato perpassa camadas de avaliação e de memória que, juntas, trabalham para a construção do olhar crítico apurado quanto aos aspectos internos e externos que compõem a telenovela 
brasileira. É, portanto, necessário saber ler esse formato. Dado que a televisão se configura como "um meio oral, e como outros discursos orais, precisa fundamentarse em fórmulas narrativas que possam ser memorizadas, ou seja, ela precisa trazer alusões a mitos, símbolos, estruturas do imaginário que sejam dadas como certas pelos receptores" (BACCEGA, 2000, p. 46). Nesse entendimento, a pergunta que nos move é apreender o que é próprio dessa crítica de telenovela e como opera a crítica contemporânea, uma vez que a internet ampliou o espaço dessas análises.

A crítica de televisão no geral possui uma questão temporal determinante, ela é feita a posteriori, após a exibição da narrativa. Pode ser realizada depois da transmissão do primeiro capítulo de uma telenovela, ou até mesmo passada uma semana de sua difusão. Diferentemente da crítica de outros produtos artísticos, essa crítica não parece induzir ao consumo da telenovela, mas antes, legitima um consumo já existente. Pode-se dizer que o leitor das análises feitas pela crítica de telenovela está em busca de legitimação dos seus argumentos, de buscar opiniões sobre o que ele está acompanhando. Notamos assim que a crítica participa do mundo dos valores de uma sociedade, sendo a telenovela um produto de grande alcance em números de audiência e de conversações tanto virtuais quanto analógicas. Nesse mundo de valores, a crítica articula a proposição daquela obra, reconhecendo as tendências e especialmente a mensagem transmitida.

\section{Estratégia metodológica}

Entendemos que toda pesquisa possui uma estratégia metodológica que é o resultado de opções e decisões feitas conscientemente e reflexivamente pelo pesquisador. Essa estratégia metodológica, em outros termos, reflete o ajustamento o mais adequado possível entre o pesquisador e o seu objeto dentro de uma pesquisa particular (LOPES, 2005).

A metodologia de pesquisa adotada consistiu em entrevistas semiestruturadas com os críticos jornalistas, sendo os dados primários compostos pelos artigos das críticas de telenovelas. Já nosso universo empírico de observação foram as críticas das telenovelas pertencentes ao prime time da TV Globo, entre os anos de 2012 e 2018, 
cujas telenovelas que tiveram maior audiência ${ }^{4}$ foram: Avenida Brasil (2012), Salve Jorge (2012-2013), Amor à vida (2013-2014), A força do querer (2017), e O outro lado do paraíso (2017-2018). A seleção para a abordagem qualitativa compreendeu dois profissionais que escrevem crítica de telenovela, a saber: Maurício Stycer (Blog do Mauricio Stycer - Uol) e Cristina Padiglione (TelePadi). Esses críticos selecionados se destacam pela sua relevância nos escritos sobre o tema, pelo tempo de trabalho na mesma atividade ou ofício de crítico e por fazerem críticas em páginas on-line. O corpus para este artigo é composto por 20 críticas de cada jornalista, sendo quatro críticas de cada telenovela, contabilizando o total de 40 críticas. Além disso, foram realizadas duas entrevistas, de forma presencial, com cada um.

O tratamento e análise desses dados se deu a partir da utilização do software de análise qualitativa Maxqda ${ }^{5}$, que permitiu chegarmos a 16 categorias empíricas. Esse processo ocorreu através da codificação dos dados, procedimento que resulta na construção e delimitação de categorias, que são compostas por um grupo de segmentos reunidos em uma mesma classe ou rubrica e são intituladas de acordo com as características que se destacam. Segundo Bardin ([1977] 2011), o processo de codificação é a classificação e o reagrupamento de elementos que atendem a critérios estabelecidos na metodologia de determinado estudo. O processo de codificação desta pesquisa teve como objetivo o refinamento dos dados colhidos: as críticas e as entrevistas. Com o cotejamento desses dados, estabelecemos as categorias que servirão de insumo para a análise de conteúdo e para estabelecermos de que forma crítica de telenovela se efetua.

A codificação dos dados realizada pelo programa passou por três estágios. O primeiro ocorreu na seleção das críticas, e a partir desta seleção e leitura construímos uma lista de temas que se sobressaíram. Em seguida, alimentamos o programa com todos os dados e a lista de códigos encontrados pela leitura. Porém, ao longo da codificação, iam surgindo novos códigos que eram inseridos. O processo de 
codificação consistiu na seleção de segmentos - frases e/ou parágrafos - identificados e relacionados a um código ou até mesmo diferentes códigos. A seleção é quantificada, ou seja, após a codificação, cada código apresenta um número total de segmentos codificados; esses códigos, posteriormente, foram denominados de categorias.

Esse processo foi realizado nos documentos das entrevistas e das críticas. Por meio dessa categorização foi possível formular os "Retratos dos documentos" de cada crítico, provenientes das categorias de conteúdo que emergiram em dois documentos, o das entrevistas e o das críticas por eles feitas. O "Retrato" consiste numa figuração visual possibilitada pelo programa Maxqda, que constrói imagens de acordo com a incidência das categorias no referido documento. Como cada categoria foi dotada de uma cor específica, cada "Retrato" evidencia a gama de cores das categorias utilizadas. Os "Retratos dos documentos" das entrevistas e das críticas foram dispostos lado a lado e esse método visual viabilizará uma ideia geral dos temas mais abordados nas críticas. Optamos por fazer a exposição de cada crítico, e, com isso, as categorias abordadas dão conta da relação entre o que foi relatado nas entrevistas e o que foi escrito nas análises.

Abaixo apresentamos a lista de categorias e suas respectivas cores:

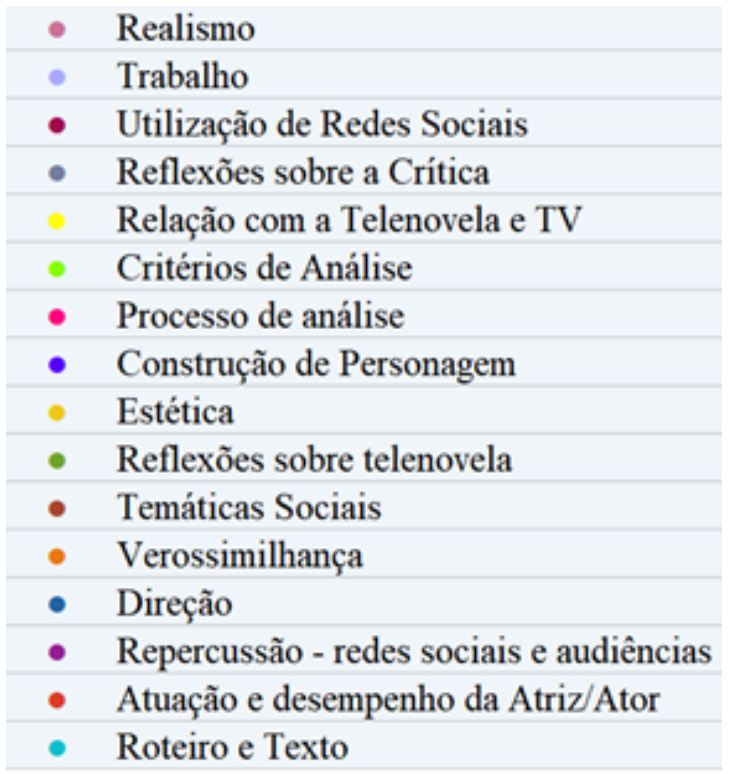

Tabela 01. Categorias e suas cores.

Fonte: Elaborado pelas autoras (Maxqda). 


\section{As críticas de Cristina Padiglioni}

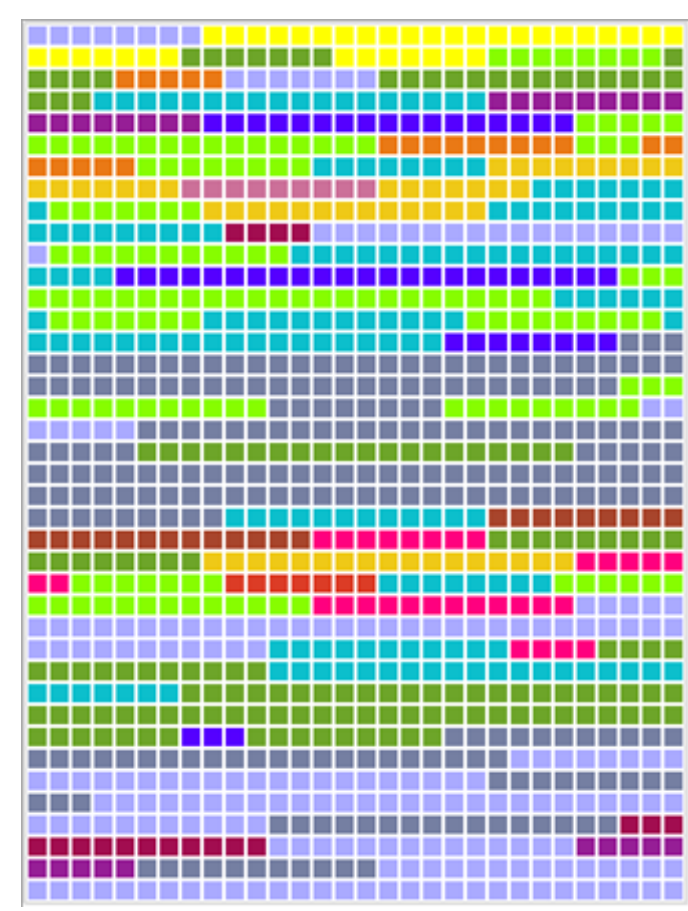

Entrevista

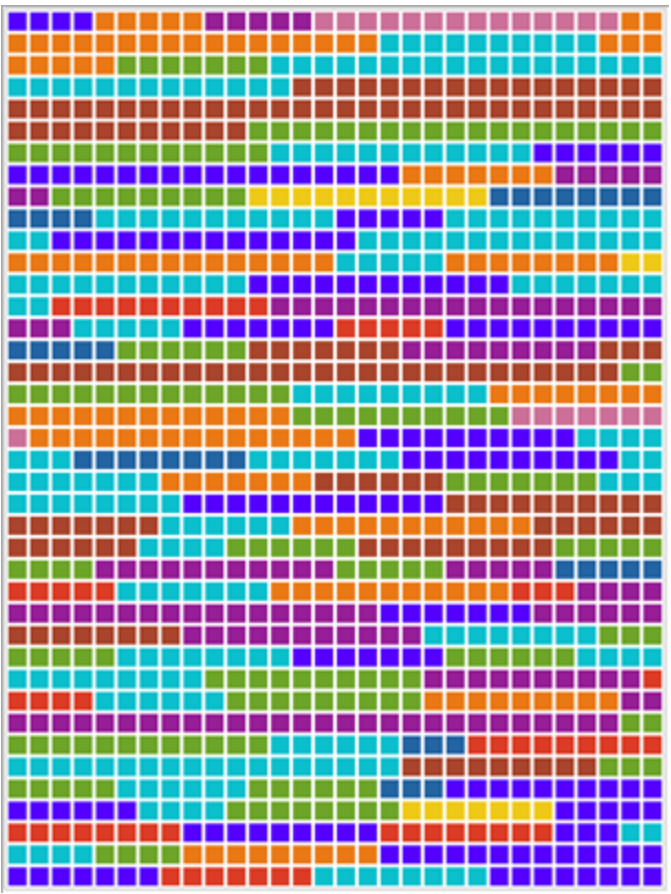

Críticas

Fonte: Elaborado pelas autoras (Maxqda).

A jornalista Cristina Padiglione iniciou sua carreira na cobertura de TV no jornal Folha da Tarde, na década de 1990. Desde então, passou pelos principais veículos de comunicação com foco no jornalismo cultural. A transição do impresso para as mídias digitais nos portais de notícias se deu a partir da página on-line do jornal O Estado de S. Paulo. Lá, a jornalista, com sua coluna, pôde abordar os assuntos centrais no que concerne à televisão, entretanto, como ela afirma, dentre os programas televisivos, "o interesse maior é sempre novela". Sua permanência no jornal perdurou até agosto de 2016, pois em outubro do mesmo ano, nasceu o TelePadi.

No "Retrato da entrevista", notamos a incidência da categoria Trabalho; sua atuação no jornalismo e na crítica de telenovela foi, de fato, um dos objetivos da entrevista semiestruturada. No caso de Padiglione, no período temporal que escolhemos para análise, houve uma mudança quanto ao local de trabalho. Logo, foi fundamental que a jornalista se dedicasse a explanar essa transferência de veículo e até mesmo de formato, haja vista que ela saiu de 
uma coluna num site de jornal para uma página somente sua, com demanda de conteúdo mais exclusiva.

A primeira linha do "Retrato de entrevista" corresponde à predominância da categoria Relação com a telenovela, e com ela vemos a influência das narrativas na construção da memória coletiva, além de instauração de hábitos de assistência, constituintes de rituais de consumo da programação televisiva. Padiglione menciona que o hábito de assistir televisão era constante em sua casa, inclusive sua mãe e tia a estimulavam a ver a telenovela, pois, devido ao trabalho, muitas vezes elas perdiam alguns capítulos.

Esse acesso à televisão - como da maioria dos brasileiros - continua contribuindo para o desenvolvimento da competência simbólica e ao acompanhamento dos diferentes canais que foram surgindo ao longo do advento da TV. Ligação afetiva é pungente e está atrelada a uma atividade que envolve membros da família no âmbito do lar. As mediações ${ }^{6}$ "ritualidade"7 e a "sociabilidade"8 (MARTÍN-BARBERO, 2018), primordiais na constituição do consumo da telenovela, iniciam-se no espaço domiciliar, e se espraiam para outros campos da vida desse indivíduo.

Ainda no "Retrato da entrevista", notamos a ocorrência da categoria Reflexão sobre a Crítica, em que foram selecionados segmentos que correspondem ao papel da crítica. Nessa categoria, foram predominantes as ponderações acerca do campo de crítica de TV no Brasil, uma reflexão de seu próprio trabalho. A reflexão está atrelada tanto à atividade da crítica bem como da relação específica com a ficção. No segmento selecionado abaixo, a jornalista menciona acerca dessa competência adquirida do assistir televisão e ficções e como isso é feito desde rede os pontos e linhas dispersos, distintos e distantes que tecem um mapa que a realidade que se constata ou a um conceito que se têm e se manipula." na memória, aos seus ritmos e formas, seus cenários de interação e repetição" (MARTÍN-BARBERO, 2018, p. 18). 
cedo pelo brasileiro, o que o torna entendedor dos mecanismos que compreendem o campo da telenovela. Como mencionado abaixo:

Eu acho que é enxergar algumas coisas que o espectador não viu. Para isso não virar uma conversa de botequim. Porque a gente tem a novela, o futebol e a música, são coisas que todo mundo entende um pouco. A gente tem quantos, sei lá, 100 milhões de técnicos de futebol, 100 milhões de autores de novela, todo mundo entende um pouco. Você vai numa reunião de pauta em jornal, ninguém se mete na pauta de economia, ninguém se mete quando o crítico de música erudita começa a falar sobre concerto do Verdi que vai chegar no municipal e que vai ser interpretado por... Mas quando você entra em novela sempre tem alguém pra dar um palpite, você em futebol todo mundo tem palpite, quando entra em música popular também é a mesma coisa. Tem algumas coisas que chamam essa conversa de botequim. São coisas que estão presentes na sua vida desde que você se entende por gente. Então todo mundo entende um pouco.

Por "conversa de botequim", a jornalista ressalta para a aptidão do brasileiro em entender os categorias e contextos do folhetim. Marcados por uma ritualidade latente, a literacia televisual é uma característica inerente de gerações que cresceram em frente da televisão, num palimpsesto contínuo, em que a televisão não acabava após o fim da transmissão, mas se desdobrava em conversações nas diferentes esferas da vida cotidiana. A circulação desse sentido dotou esse espectador de uma gama extensa de repertório. Entretanto, ressaltamos que somente esse acervo simbólico não o faz capaz de analisar uma obra, deve-se ter em conta outros fatores condizentes com o fazer da crítica.

A categoria Reflexão sobre a telenovela dá pistas sobre as características e argumentos que surgiram na análise do folhetim. Os pontos mais relevantes foram a configuração dos capítulos, ao formato em si e o entendimento de que telenovela é uma obra de ficção e está inserida numa indústria particular que tem em vista o lucro de seus produtos. No fragmento abaixo explana:

No sentido de que ele escolhe a série que ele vai ver, a novela um pouco assalta quem está no sofá. É uma hora que você fala assim: "ah eu não tenho nada para fazer, vou ver novela", ou então "eu não quero pensar em nada", ou eu já vi gente assim: "a novela é tão ruim que eu adoro ver, porque eu quero não pensar em nada; não quero novela engajada 
pra pensar em coisa nenhum eu quero só sentar e quero tudo mastigado". Tem isso! Tem esse público que não quer pensar em nada. Então, ele é um pouco assaltado nesse sentido. A novela entra muito por inércia, a série é um negócio que o cara vai muito buscar.

Ela explica que as novelas estão presentes na vida diária do brasileiro, mas que, devido a essa facilidade, há certos elementos que passam despercebidos e que a crítica deve "trazer essas coisas que não estão sendo vistas". Ao levantar isso nas suas análises, possibilita uma crítica que dialoga com as questões pertencentes às gramáticas de produção (VERÓN, 1987), com as diferentes condições que envolvem produzir uma telenovela, e as gramáticas de reconhecimento abarcadas nas suas avaliações, que entram em contato com as gramáticas de reconhecimento de seus leitores-espectadores.

O Critério de análise é formado pelos segmentos que concernem aos parâmetros de análise adotados pelo profissional. Visto somente no documento das entrevistas, a categoria aponta para as normas e fundamentos empregados nas avaliações. Esses parâmetros não foram em tese detalhados, pois, de acordo com cada telenovela, a leitura é feita de uma forma. Entretanto, Padiglione costuma ressaltar a organicidade, ponto que, para ela, é essencial que uma novela tenha. Segundo ela, a organicidade está em conjunção com a verossimilhança, seria apresentar uma trama que faça sentido dentro da narrativa proposta.

\footnotetext{
A organicidade pode-se dizer que eu levo em conta isso. Inclusive os diálogos, se você ouve aquele diálogo e pensa "nossa isso poderia estar acontecendo do meu lado", eu adoro isso, é uma coisa que me encanta profundamente. Que faz você embarcar numa história. Então eu levo muito na emoção, desde que tenha lógica. Não dá para ser um negócio completamente fora de propósito.
}

Mesmo alertando para o caráter da telenovela como ficção, a jornalista censura histórias que fogem do escopo pretendido: "Eu levo em consideração se ela é panfletária ou não, porque não basta que ela tenha uma boa mensagem social, se ela for panfletária ela é um recado quase perdido".

No "Retrato das críticas", vemos a ocorrência das categorias Construção do personagem e Roteiro e texto, esta última também presente no "Retrato das 
entrevistas", mas em menor quantidade. As duas categorias trazem semelhanças, pois cabe ao ator dar vida ao roteiro proposto, entretanto, o que remarcamos como Construção de personagem diz respeito às variadas reviravoltas que envolvem um personagem durante a telenovela. Porém, ressaltamos que, numa produção de longa serialização, é possível, dentro da história, a transformação dos personagens, devido às viradas na narrativa, às passagens de tempo e outras mudanças previstas no roteiro. Assim, um personagem bem construído admite várias camadas que vão aparecendo no decorrer do folhetim, mas que, ao mesmo tempo, façam sentido na ficção. A crítica de Padiglione reivindica esse bom senso das ficções que são objeto de seu escrutínio. A informante remarca para determinados pontos da trama, chamando a atenção do leitor para algo que possa ter ficado subentendido. Tais os exemplos abaixo:

Temos ali um vilão que se redimiu, um grande ator a sustentar o personagem e sua virada (Félix/Mateus Solano), e um bom rapaz, disposto desde o início da história a constituir família, como se diz, com filhos e relação conjugal estável, mas ciente de que não poderá gerar uma criança apenas com o parceiro, homem como ele (Niko, Carneirinho/Thiago Fragoso).

A protagonista da trama de O outro lado do paraíso, Clara, foi uma das abordagens de Padiglione acerca da construção de seu papel, pautado nas análises da crítica desde o início da ficção, especialmente no tange ao vocabulário utilizado pela mocinha. Outro personagem da trama escrutinado pela jornalista foi Renato, médico dedicado e interesse amoroso da protagonista, que, sem preparação do público, mostra-se um dos vilões da trama. "Único personagem que parecia dúbio em O outro lado do paraíso, Renato, interpretado por Rafael Cardoso, acaba de se revelar malvado, muito malvado. Nuance para quê?"

Em lugares pontuais no "Retrato das entrevistas", a Verossimilhança aparece bem distribuída no "Retrato das críticas", é nessa categoria que, em nosso entender, a autora cobra certa veracidade da narrativa que está sendo apresentada. Esse foi um ponto abarcado nas diferentes análises em telenovelas distintas. A categoria, fortemente atrelada a Roteiro e texto e Construção do Personagem, mostra-se 
como questão central de análise da teledramaturgia, como na cena emblemática do primeiro beijo gay da emissora: "O beijo gay, primeiro na história da produção que reúne a maior plateia do País, veio emoldurado nesse contexto de família de comercial de margarina, no sentido mais conservador do termo: filhos, união estável, amor, casa, afeto, lealdade e juras eternas". Nesse segmento, sobre Amor à vida, Padiglione alerta que, por mais avanços no campo da diversidade, e por ter narrado a história de um personagem homossexual, alguns aspectos da trama apresentavam um pensamento com resquícios do conservadorismo brasileiro, o que, aparentemente, pavimentou a aceitação da cena nos públicos mais conservadores.

A Atuação, categoria em vermelho, apresenta as críticas feitas à interpretação de determinado ator na trama. De acordo com Pallottini (1998, p. 140), "um bom ator salva um mau personagem e, ao contrário, um mau ator enterra um bom personagem; a má escalação de um elenco pode pôr a perder um bom trabalho". Pela durabilidade das telenovelas, a quantidade de vezes que entramos em contanto com aquele ator entremeado nessa história intensifica a sensação de proximidade com o personagem. Isso pode ser notado na escalação de Adriana Esteves para a vilã de Avenida Brasil:

Carminha, como revelou o diretor de núcleo Ricardo Waddington, pedia uma atriz com carisma de heroína. Alguém que arranca a cabeça da boneca da enteada no primeiro capítulo tinha de cativar o público por algum outro fator, e Adriana ganhou a plateia de cara, mesmo com (ou talvez por isso mesmo) aquela atrocidade.

A Repercussão representa os segmentos que trataram tanto da audiência tradicional quanto da ressonância das narrativas em redes sociais. A categoria é percebida nos dois documentos, entretanto é mais frequente nas críticas, onde a jornalista costuma relatar os pontos de audiência da semana analisada ou de uma cena importante. Os pontos de audiência, métrica usual da Kantar Ibope, consiste na verificação de índices de programas televisivos. A telenovela, estando no horário nobre da televisão, na faixa horária de maior rentabilidade em termos de assistência, ainda tem o horário das 21 horas com um dos mais visualizados. 
Portanto, é comum a métrica ainda ser relatada em matérias jornalísticas e nas críticas. Todavia, outra maneira de trabalhar com a repercussão de uma ficção são as redes sociais, especialmente o Twitter.

Da conversa na padaria e no escritório, o "debate" sobre mocinhos e vilões se estendeu a fóruns públicos, graças à expansão da web, multiplicando opiniões, pontos de vista, soluções e piadas em torno do script. Quem jamais pensou em convidar outros autores, atores, políticos e jornalistas para ver novela em casa, hoje divide o sofá até com o Nilo (José de Abreu), compulsivo tuiteiro, e sabe do que se ocupa o agora vereador Andrea Matarazzo quando zapeia das eleições para a mansão do Tufão.

\section{Maurício Stycer e a crítica}

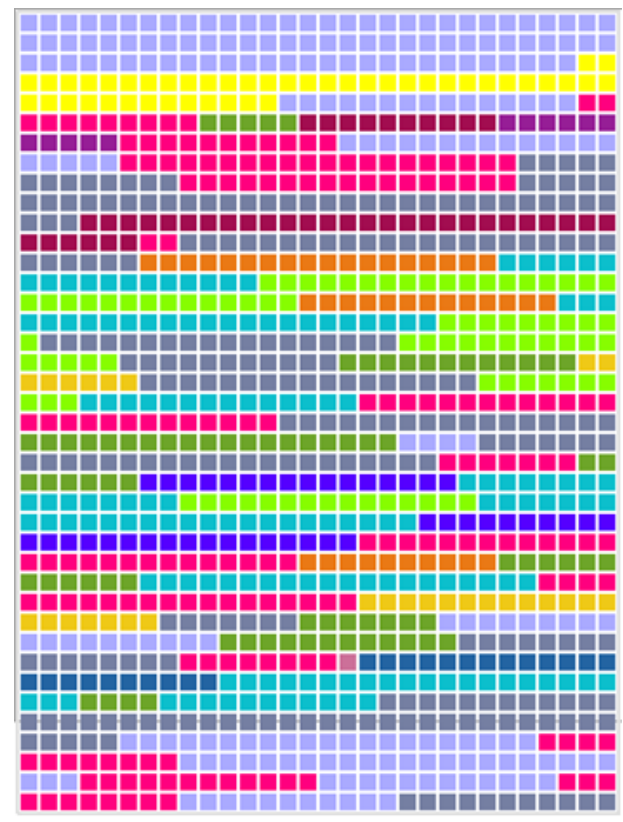

Entrevista

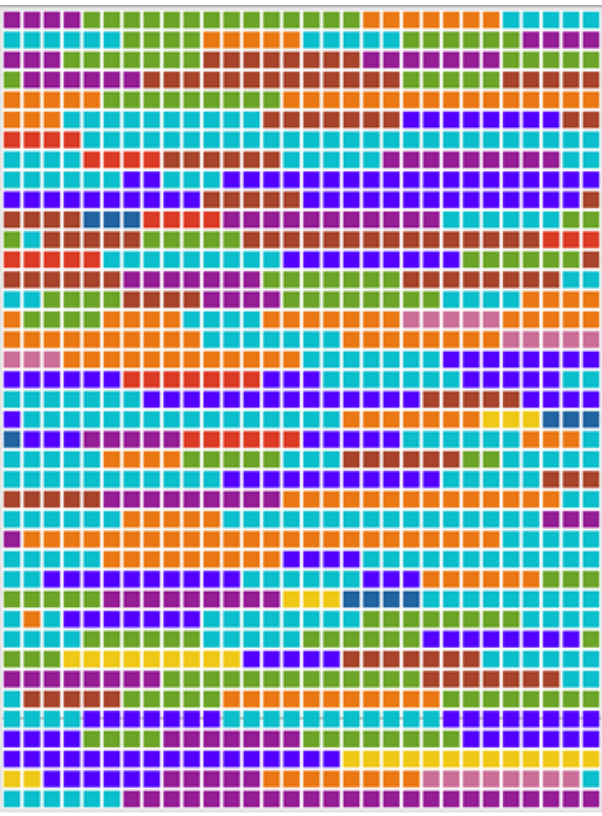

Críticas

Fonte: Elaborado pelas autoras (Maxqda).

A primeira formação acadêmica de Maurício Stycer foi em Economia e somente em seguida cursou Comunicação Social, com habilitação em Jornalismo. Seu interesse pela área advém do desejo de ser jornalista cultural, o que logo mais foi possível com sua entrada no jornal O Globo, no Caderno B, em 1989. Sua entrada nos portais de notícias nas mídias digitais foi no IG, em 2008, onde criou um blog que servia de complemento de suas matérias no portal de notícias. Nesse 
espaço, como ele comenta, era feito um making of das matérias que considerava relevante, e isso perdurou por um ano e meio.

Sua entrada no UOL, pertencente ao conglomerado do Grupo Folha, iniciouse em 2010, tendo como foco a TV aberta, mesmo abordando outros assuntos em reportagens. Seu blog, como ainda é exibido na página, versa acerca dos mais variados programas da televisão. Entretanto, como ele indica, "novela é um assunto fora da novela", assim procurava estar inteirado de todas as estreias de ficção.

O que se sobressai na entrevista de Stycer é a recorrência das categorias Processo de análise, Reflexão sobre a crítica e Trabalho. Percebemos que essas categorias abordam o ofício do crítico, especialmente da sua trajetória no jornalismo, sua relação com a televisão e como se configura seu processo de avaliação dos programas televisivos. Relatamos que as entrevistas foram realizadas com o intuito de complementar o entendimento acerca das críticas, aprofundando o conhecimento sobre sua atividade na área. Nesse sentido, no "Retrato da entrevista", a ponderação acerca da crítica é marcante e está intrinsecamente ligada à ocupação do jornalista.

A categoria Trabalho no "Retrato da entrevista" mostra que a atuação de Stycer em seu blog, até o ano de 2018, ia além das postagens, pois até essa data ele era o moderador dos comentários realizados ao fim das publicações. A atividade de moderar, segundo ele, ajudou na modulação de seu texto, aprendendo a mudar o tom de sua crítica, que, até então, ele acreditava ser muito duro e enfático em suas opiniões. Todavia, acredita que deve sempre dizer ao telespectador que o programa é ruim, mesmo que ele o aprecie.

Em cor vermelha escura, a Utilização de redes sociais demonstra o uso do Twitter pelo crítico, espaço em que são construídos um diálogo e a possibilidade de assistir ao programa com inúmeras pessoas. Para ele se tornou uma ferramenta importante de trabalho e formalizou uma experiência de processo colaborativo. Sobre essa característica, o crítico narra: "Fui levado ao Twitter, inicialmente, pela vontade de promover os textos que promovia no blog. Era (e ainda é) uma oportunidade de 
mostrar meu trabalho a uma audiência que não o conhecia. Rapidamente, porém, entendi essa função secundária da rede social" (STYCER, 2016, p. 39).

E desde o início eu percebi esse diálogo, essa experiência que é incrível de você assistir televisão como se você estivesse numa sala com várias pessoas ao mesmo tempo. Todo mundo vendo a mesma coisa. Isso realmente é uma experiência incrível. Então o Twitter é uma ferramenta muito importante para o meu trabalho. Aprendo, recebo dicas, ouço reprimendas, corrijo coisas em função de comentários, já muitas vezes ocorreu, apontando erros, imprecisões.

A Reflexão sobre a crítica é recorrente em variados pontos do documento. Isso indica a observação e a ponderação acerca de sua própria atividade. Stycer acredita que a crítica afeta muito pouco o processo de criação da telenovela. A crítica, por sua vez, está mais voltada para o espectador, ajudando-o a entender seus gostos e até mesmo mostrar uma "intenção oculta" por parte da produção. A contextualização foi o argumento-chave empregado para exercer a atividade de crítico, e conforme sublinhamos, a crítica tem como características explicar o contexto em que determinada obra está sendo lançada. Isso posto, Stycer analisa os truques das ficções, especialmente as tramas naturalistas, sujeitas à crítica contextual. Para ofertar esse olhar, deve haver, tal como ele enumera, "didatismo, sensibilidade e clareza", saber comunicar sobre um tema mesmo que o telespectador ignore e não esteja vendo.

Um eu já falei, acho que é a questão do contexto, isso eu acho essencial. Acho que você precisa ser didático, claro. Tem um lado do trabalho do crítico que é difícil explicar, eu chamo que é um pouco a sensibilidade, que é sua relação subjetiva que você tem ali, com o assunto, com a interpretação, que comove a uns e não comove a outros, atinge alguns e não atinge outros. E saber comunicar isso para o leitor também, deixar claro que às vezes determinado assunto, determinada interpretação, determinado ator, está transmitindo algo diferente, mesmo que ele não esteja vendo isso. Mas é uma carga de subjetividade. Aí é um terreno pantanoso.

Ponderar acerca da crítica levou Stycer a aludir que o telespectador, em certos casos, possui uma "atitude conformista". Isso se explica porque a 
telenovela reconforta, e, em algumas ocasiões, não há o interesse de adentrar nas temáticas sociais abarcadas em cena, mas somente utilizar as ficções como uma fonte de entretenimento. Dessa maneira, ele busca não ter medo de arriscar e expor uma opinião, que pode não ser bem interpretada, seja pelo público ou pelo autor.

É um requisito, respondendo a sua pergunta, é mostrar muitas vezes o que não está na aparência. Tentar mostrar para o espectador eventualmente o que ele não esteja vendo. Não ter medo de ir contra a corrente, acho isso fundamental. Não ter medo de arriscar as suas opiniões, por exemplo. o Sétimo Guardião eu fui a única pessoa que elogiou no início, já de cara todo mundo saiu matando. Eu vi uma coisa ali que me interessou pessoalmente, tentei mostrar para as pessoas. Tentei fazer uma reflexão por que ele [o autor] está voltando a isso, é um subgênero que está meio morto na teledramaturgia.

"A crítica é o patinho feio". Essa afirmação está no centro do que Stycer se refere como sendo o preconceito com a televisão, sempre vista como "algo menor, menos importante" (2016, p. 17). As razões para isso, em sua opinião, é que a TV aberta entra na casa dos espectadores de graça e se configura como um entretenimento democrático, isso permitiu que as pessoas construíssem um repertório extenso acerca das ficções. Levando isso em conta, há a percepção de que, para escrever sobre televisão, é necessário assistir muito, e com isso seria simples efetuar uma análise.

Apesar desses entraves, o crítico explica que seu trabalho é reconhecido pelo grau de exigência, algo percebido por produtores e autores, o que demonstra uma compreensão do trabalho realizado. O rigor na confecção de suas avaliações e a honestidade são dois pontos que ele costuma notar quando aludem sobre seu trabalho. Pois ele parte do princípio de que o papel do crítico não é sempre falar mal, como é comumente difundido, e sim desvendar um texto.

A categoria Reflexões sobre a telenovela, presente em múltiplos pontos dos dois "Retratos", enuncia a inquietação de estar a todo instante refletindo acerca do folhetim e seus desdobramentos nos meses de exibição. Observamos que essa categoria é mais evidente no "Retrato das críticas", onde as publicações periódicas 
apontam e descrevem aspectos abarcados nas cenas. Um dos pontos enumerados nos dois documentos foi o fato da telenovela ser uma obra aberta, o que autoriza o autor a efetuar, de acordo com suas necessidades, alterações significativas.

Em ambos os "Retratos dos documentos", da entrevista e das críticas, a Verossimilhança é visível. A categoria assinala para a cobrança do crítico nesse aspecto chave das narrativas, pois a verossimilhança está atrelada à ideia da mimese aristotélica, na imitação do real. Entretanto, esse real nem sempre diz respeito à noção de realidade entendida no contexto social real, mas na veracidade construída naquela narrativa. As noções de construção de mundos (RYAN, 2012) e mundos possíveis (ECO, [1987] 2002) nos revelam que a narrativa tem que fazer sentido na proposição de mundo no qual foi criado, ou seja, ser verdadeiro aos elementos nos quais se propôs a construir, como no caso da crítica à Avenida Brasil:

Nina, moça moderna, bem informada, jamais faria a opção primária que fez. Não custa lembrar que, no início da novela, a personagem se aproximou da família de Tufão ficando amiga de Ivana em salas de batepapo na internet. É evidente que o autor sabe disso. Por que, então, foi por este caminho? Só vejo uma resposta: a necessidade de esticar a trama de Avenida Brasil.

Em seu modelo de promessa, Jost explica que o receptor tem o direito de exigir, sendo que a promessa é uma via de dois lados, o da produção e da recepção. Por conseguinte, o espectador exige que a ficção respeite uma regra fundamental: "A da coerência do universo criado com os postulados e as propriedades que o fundam" (2007, p. 37). Com isso, Stycer ressalta para a realização de entretenimento com "certo grau de inteligência", que foge de um modelo de telenovela engessado e que busque fugir da repetição:

Tenho certa preocupação com isso, porque as novelas quase todas se pretendem realistas, então acho que elas ficam um pouco sujeitas a essa crítica, a questão da verossimilhança, da possibilidade de realmente disso estar acontecendo. Você falou que um dos casos que você está estudando é Salve Jorge uma novela que abusou disso; e é interessante você ver que sempre a defesa que a Glória Perez fez foi "não, mas eu tenho uma história assim de uma pessoa que fez isso". 
Atrelada à categoria Texto e roteiro, a categoria Construção do personagem foi relatado nos dois documentos. As duas categorias são, de longe, o caminho mais usual para se tratar um folhetim. Texto e roteiro fala de conteúdo, enquanto Construção de personagem contempla majoritariamente a performance. Stycer, na crítica a seguir, apresenta as personagens de $A$ força do querer, e, a partir de sua intepretação, vai qualificando as ações de cada ser fictício:

\begin{abstract}
Ritinha (Isis Valverde) é a sereia que seduz dois homens, o chucro Zeca (Marco Pigossi) e o riquinho Ruy (Fiuk), e faz gato e sapato de ambos. Bibi (Juliana Paes) trocou um homem rico, Caio (Rodrigo Lombardi), por um pobretão, Rubinho (Emilio Dantas), por paixão. Jeiza (Paola Oliveira) é PM, luta MMA e não tem medo de cara feia. E mais. Silvana (Lilia Cabral), jogadora compulsiva, ignora a pressão do marido rico e poderoso, Eurico (Humberto Martins). Joyce (Maria Fernanda Cândido) é a "perua" que dedicou a vida à futilidade com uma convicção de guerreira. Irene (Débora Falabella) parece ser uma maluca esclarecida, dedicada a viver uma "atração fatal" com o marido das outras.
\end{abstract}

Texto e roteiro e Verossimilhança foram as categorias que apareceram nos dois documentos. Como relatamos, as duas se configuram como elementos técnicos, tendo em vista que, numa narrativa, a coerência é um atributo necessário para o estabelecimento do "pacto de recepção" (LOPES, 2009). Na crítica "Tiro, porrada e Bomba" (STYCER, 2016, p. 121), temos um exemplo do que se refere às duas categorias:

\footnotetext{
Amor à vida, de Walcyr Carrasco, foi outra novela que apostou nessa política de choque, com um texto de baixa qualidade, sem substância. $O$ resultado, em termos de Ibope, foi um pouco melhor do que Salve Jorge, de Glória Perez, uma novela com história bem mais rica, mas problemas sérios de lógica.
}

Quando interpelamos o crítico sobre o que ele considera um texto de qualidade, ele relembra da aptidão dos textos de autores já consagrados, como Manuel Carlos. Uma das características das telenovelas é o primor pela ação, que, em certos casos, acontece em detrimento do texto. O que se percebe na telenovela das nove é a ênfase em ficções aceleradas e dinâmicas, todavia há autores que conseguem realizar esse casamento entre ação e texto de qualidade. 
Porém, em muitos casos, quem se submete à desvalorização é o texto. Em sua primeira crítica sobre Avenida Brasil, Stycer indica: "Nos primeiros seis capítulos e meio, João Emanuel Carneiro promoveu um festival de acontecimentos e exageros poucas vezes visto de forma tão vertiginosa numa novela". Nesse entendimento, Stycer argumenta que:

As novelas da Lícia Manzo têm uma característica nova que elas trazem. Quer dizer, nova não, tem muito de novela do Manoel Carlos que é a coisa do diálogo caprichado, da conversa, novela no gogo. Ela, acho que tem uma habilidade incrível, a maneira dela fazer você ficar assistindo 30 a 40 minutos só de pessoas conversando, "sem ação". Acho incrível, é uma coisa muito interessante.

Acreditamos que os "Retratos dos documentos" nos possibilitam uma maneira de realizar uma análise interpretativa, não necessariamente comparativa, pois são documentos completamente distintos, mas um olhar para a criação e o criador. Os críticos aludem à telenovela como insumo para seus próprios textos, e até mesmo na função de representante dos espectadores, ao cobrar do campo da produção a coerência e a qualidade. Nas entrevistas, Stycer afirma que acha desleal fazer uma crítica de primeiro capítulo; e que para ser justo, somente escreve uma ou duas semanas após a estreia, pois depois desse período, já possui conteúdo suficiente para realizar uma análise.

\section{Apontamentos finais}

As categorias elaboradas neste artigo têm por intuito proporcionar parâmetros de análise para o estudo da crítica de telenovela; assim, separamos as categorias em três grandes conjuntos, que em nosso entender, correspondem a três grandes categorias de análise em que as críticas de telenovela podem ser abarcadas. O objetivo não é dar peso para cada grupo, mas sim, apresentar pontos de aproximação em que as análises podem ser tratadas. Com salientamos, esses dados e logo a categorização, foram construídos a partir de nossa base de dados coletados desses dois críticos e de cinco telenovelas do horário nobre 
brasileiro, que foram representativas, isto é, com maior audiência no período entre 2012 a 2018. Nossa finalidade não é divulgar um manual definitivo acerca da análise da crítica de telenovela, todavia, indicar algumas pistas metodológicas advindas de uma cartografia da crítica e de críticos. Nesse sentido, reunimos em três grupos as categorias explicadas a seguir:

As categorias técnicas (Roteiro e texto, Verossimilhança, Temáticas sociais, Construção de personagem, Repercussão, Atuação e desempenho da atriz/ator, Direção e estética), são intrínsecos ao entendimento do potencial cognitivo da telenovela, isto é, a criticabilidade de uma obra (CASTRO, 2014, p. 21). A própria existência de uma crítica voltada para a teleficção já se torna uma constatação dos atributos reflexivos e artísticos desse produto. Sem levarmos em consideração a ficção como um produto da indústria cultural, pensamos na telenovela como uma produção que admite um lado mercadológico, pois visa à comercialização; e do ponto de vista do entretenimento, que, pelo naturalismo, discute temas importantes da sociedade. Benjamin chega a afirmar que "o aspecto decisivo da atividade crítica é o de saber se ela se fundamenta numa análise objetiva, num plano estratégico que contenha em si mesmo uma lógica e uma honestidade próprias" (2018, p. 107); por essas categorias temos uma noção das estratégias e dos eixos principais de análise que levam para a argumentação central das críticas.

Nas críticas analisadas, percebemos como um artifício de argumentação a citação de algumas partes da narrativa retirando a imagem e dando ênfase ao texto. A intenção de elucidar essas cenas é, em sua maioria, uma maneira de contribuir para realçar a percepção do leitor, que aliado à descrição e uma foto eventual, focaliza nos aspectos tratados na análise. Benjamin (2018, p. 114) distingue que "não pode haver crítica sem pelo menos uma citação da obra que é recenseada"; assim, as críticas usualmente demonstravam seus pontos de vistas por meio da inserção de trechos da narrativa fundamentando sua premissa.

As categorias reflexivas (Reflexões sobre a telenovela, Reflexões sobre a crítica, Processo de análise, Critérios de análise e Relação com a telenovela) 
enumeram práticas socioculturais que incidem nas análises críticas. Vinculadas à ideia de "habitus" (BOURDIEU, 2011), esse conjunto de categorias é um registro de novas configurações, ritualidades ${ }^{9}$, sociabilidades e tecnicidades ${ }^{10}$ (MARTÍN-BARBERO, 2018). Ao contrário do primeiro grupo de categorias, que se voltava para os eixos técnicos da crítica, esse grupo se pauta pelo aspecto subjetivo e reflexivo das análises. Castro (2014, p. 9) afirma que a crítica é "recorte cifrado de sua própria experiência, de sua visão de mundo, suas escolhas, seu percurso formativo", assim sublinhamos o caráter abstrato da confecção da crítica.

Das críticas analisadas, é evidente o afunilamento dos temas abordados, tendo em vista que cada crítica se volta para um único tema ou versa sobre questões afins. Tal como relatado pelos profissionais, a busca de pauta decorre, em muitos casos, da interação com o público, seja em comentários ou em redes sociais, é recorrente dissertar sobre um determinado tema que se destacou na semana ou em um único capítulo. Até mesmo a partir de uma única temática, o crítico pode estender a análise para várias narrativas.

No caso das categorias apresentadas neste estudo, a reflexão foi a chave para juntá-los nesse grupo, pois, em todos os segmentos codificados, visualizamos uma tentativa de ponderar acerca da própria profissão, sua vivência no jornalismo e como crítico, logo executar uma metacrítica. A reflexividade presente nas críticas está inserida no próprio intento de relatar ao público o que está subentendido nas tramas e ainda no campo da produção. Nesses fragmentos de autoavaliação ficam implícitas as condições de fala dos profissionais, sua aderência no campo, seu arcabouço simbólico sobre televisão, sua visão de mundo e seu sentido de gosto. 
Sartre (2015, p. 27) aborda o problema da subjetividade a partir da filosofia marxista e afirma que "quando se fala de subjetividade, fala-se de certo tipo, como veremos, de ação interna, de um sistema, de um sistema de interioridades, e não de uma ação imediata com o sujeito". A subjetividade, assim como o habitus, pode ser entendida a partir das ações internas e a relação com o social. Nessas percepções emerge a questão do juízo de gosto, que, na noção de Bourdieu, constrói-se tanto pelas condições materiais quanto por condições do campo simbólico, edificadas pelas instituições que fomentam as competências culturais.

As categorias de Práticas profissionais (Trabalho e Utilização de redes sociais) representam o fluxo de trabalho e a atuação no campo da crítica, haja vista que apontam para as particularidades da atividade crítica, incluindo mediações das novas espacialidades ${ }^{11}$ e temporalidades ${ }^{12}$ (MARTÍN-BARBERO, 2018). Cada crítico estudado possui uma jornada de trabalho distinta e a divide com outras atividades que são complementares.

Além de mudanças espaciais e físicas, notamos a abrangência da espacialidade virtual engendrada pelas tecnicidades. Foi nas mídias sociais digitais que a ressonância das críticas de televisão alcançou novos patamares, o que ocasionou diferentes temporalidades dentro do escopo do jornalismo cultural. As análises de telenovelas são trabalhadas a posteriori, logo estão sujeitas ao tempo das telenovelas em sua forma de exibição na televisão aberta. Por conseguinte, com o advento do streaming, novas estratégias mercadológicas de lançamento das ficções são combinadas ao modelo clássico da programação estática, como as estreias das tramas primeiramente na plataforma de streaming da emissora anteriormente à sua exibição na TV aberta, como foi o caso da telenovela das $18 \mathrm{~h}$, habitado do território feito de proximidade e pertencimento; o espaço comunicacional que tecem redes eletrônicas; o espaço imaginado da nação e de sua identidade; espaço praticado da cidade moderna, com a subjetividade que emerge das novas relações com a cidade e dos modos de sua apropriação". 
Órfãos da terra (Globo, 2018). Logo, a temporalidade do crítico se refere a dois aspectos: ao seu tempo de assistência dos programas e ao seu tempo de escrita e publicação. Sabemos que a primeira interessa ao período disposto para assistir a um determinado número de programas, seja ficção, variedades ou até notícias. Esse tempo libera certos aspectos que vão transparecer na análise e para a captura de elementos significativos à avaliação.

Por fim, este artigo traz pistas metodológicas para trabalhos semelhantes no estudo da crítica de telenovela. Observamos que essa crítica é uma atividade simbiótica entre os profissionais que a efetuam e o público leitor-espectador. A crítica também é um texto incompleto, as análises são realizadas somente do material visto até aquele instante da transmissão. Lida separadamente, ela não fornece subsídios para o todo da narrativa, pois é feita de retalhos.

\section{Referências}

BACCEGA, M. A. Crítica de televisão: aproximações. In: MARTINS, M. H. (org.). Outras leituras: literatura, televisão, jornalismo de arte e cultura, linguagens interagentes. São Paulo: Instituto Cultural Itaú, 2000.

BENJAMIN, W. Linguagem, tradução, literatura (filosofia, teoria e crítica). Belo Horizonte: Autêntica, 2018.

BOURDIEU, P. Gostos de classe e estilos de vida. In: ORTIZ, R. (org.). Pierre Bourdieu: sociologia. São Paulo: Ática, 1993.

BARDIN, L. Análise de conteúdo. São Paulo: Edições 70, 2011.

CANDIDO, A. Literatura e sociedade: estudos de teoria e história literária. 3a. ed. São Paulo: Editora Nacional, 1973. 
CASTRO, E. G. A aprendizagem da crítica: literatura e história em Walter Benjamin e Antonio Candido. São Paulo: Fapesp/Intermeios, 2014.

CHARAUDEAU, P. Discurso das mídias. São Paulo: Contexto, 2006.

ECO, U. Lector in fabula. São Paulo: Perspectiva, 2002.

GOMES, M. Ao abrigo dos discursos circulantes. Revista Rumores, ano 6, n. 2, jul.-dez. 2012. Disponível em: https://doi.org/10.11606/issn.1982-677X.rum.2012.55290.

JOST, F. Seis lições sobre a televisão. Porto Alegre: Sulina, 2004.

LOPES, M. I. V. "Telenovela como recurso comunicativo". Matrizes v. 3, n. 1, p. $21-47,2009$.

. A teoria barberiana da comunicação. Revista Matrizes, v. 13, n. 1, 2018.

Pesquisa em comunicação. 8a . ed. São Paulo, Loyola, 2005.

MARTÍN-BARBERO, J. 7a. ed. Dos meios às mediações: comunicação, cultura e hegemonia. Rio de Janeiro: UFRJ, 2015.

. Dos meios às mediações: três introduções. Revista Matrizes, v. 13, n. 1, 2018.

PALLOTTINI, R. Dramaturgia de televisão. São Paulo: Moderna, 1998.

RYAN, M. L. Story/Worlds/media: turning the instruments of a mediaconscious narratology. In: RYAN, M. L.; THON, J. Storyworlds across media. Lincoln/London: University Nebraska Press, 2014. 
SARTRE, J.-P. O que é a subjetividade? Rio de Janeiro: Nova Fronteira, 2015.

STYCER, M. Adeus, controle remoto: uma crônica do fim da TV como a conhecemos. São Paulo: Arquipélago, 2016.

VERÓN, E. La semiosis social: fragmentos de uma teoria de la discursividad. Argentina: Gedisa, 1987.

Submetido em: 2 set. 20 | aprovado em: 14 out. 20 